\title{
Biodynamic Model of the Seated Human Body under the Vertical Whole Body Vibration Exposure
}

\author{
Vikas Kumar \\ Department of Mechanical Engineering, Amity University, Uttar Pradesh (AUUP), NOIDA, India. \\ V. Huzur Saran \\ Mechanical and Industrial Engineering Department, Indian Institute of Technology, Roorkee, India.
}

(Received 13 January 2017; accepted 15 February 2019)

\begin{abstract}
The seat-to-head transmissibility and apparent mass characteristics are measured for the seated human subjects exposed to vertical whole-body vibration in the $0.5-20 \mathrm{~Hz}$ frequency range at a vibration magnitude of $1.0 \mathrm{~m} / \mathrm{s}^{2}$ rms. The experiments are conducted on test subjects seated in an upright posture. A biodynamic model has been developed for bio-mechanical parameters that are estimated on the basis of identified biodynamic responses. The parameters identification technique employs a genetic algorithm for the solution of the function comprising sum of squared magnitude and phase errors related with target values of seat-to-head transmissibility and apparent mass. The developed model presents the target values of magnitude associated with apparent mass and seat-tohead transmissibility. The natural frequencies of the model have been found at up to $5.0896 \mathrm{~Hz}$. The model also presents the resonant frequencies calculated on the basis of both biodynamic response functions very close to that found for seated human body experimentally.
\end{abstract}

\section{INTRODUCTION}

The moving vehicle parts, suspension system and vehicleterrain interactions cause vibrations in the vehicle compartment. During the journey, drivers and passengers are exposed to low frequency vibrations i.e. frequencies up to $20 \mathrm{~Hz}$. The vibrations are transmitted to the human body from the various interfaces of human body and vehicle parts such as floor, seat and backrest etc. Researchers noted that these vibrations have ill-effects on the driver as well as on the passengers such as discomfort, impaired performance and health effects. ${ }^{1-3}$ The effects of whole body vibration (WBV) vary with amplitude, frequency, type of vibration, subject's mass, height, sex etc. A large number of variables play their role in the human body dynamics under the exposure of whole body vibration. Various past studies have attempted to quantify the effects of whole body vibration by considering above stated variables, with the help of frequency response functions such as seat-to-head transmissibility (STHT), driving-point mechanical impedance (DPMI) and Apparent mass (APMS). ${ }^{3-5}$

The human body is very complex in nature and considerable variations in dynamic response have been observed above the $2 \mathrm{~Hz}$ frequency of whole body vibration. ${ }^{6}$ During the development of a vehicle seat system, computer simulations of the human body and seat systems are essential for predicting the dynamic responses. In order to perform computer simulations, a dynamic model of the human body, along with the seat, is required. Various models of the human body under WBV exposure have been proposed in the literature. ${ }^{7,8}$ Many models are based upon the frequency response functions. The restoring and damping parameters of the human body model are calculated by matching the model dynamic response with one or two of the frequency responses: STHT, DPMI and APMS.
These reported human body models vary from single degreeof-freedom (DOF) to linear \& non-linear multi-DOF models.

A two-DOF mechanical simulator has been proposed to account human body dynamics for testing seat dynamics under the exposure of vibration. ${ }^{9}$ Seat performance of the vehicle not only depends upon the design of seat suspension system but also on the dynamics of seated human body. ${ }^{2,3}$

A Six-DOF non-linear lumped parameter model was proposed by Muksian and Nash. ${ }^{10}$ The lumped masses were connected by restoring and damping elements, representing the elastic and damping properties of the connective tissue between the body segments. Muksian and Nash recognized the possibility of a frequency dependent damping coefficient in accord to frequency dependent muscle forces. ${ }^{11}$ The model proposed by Muksian and Nash was lumped together with the tractor's seat, ${ }^{10}$ chassis and tires by Patil and Palanichamy. ${ }^{12}$ Qassem et al. proposed an eleven-DOF linear model for the seated human body under the exposure of vibration. ${ }^{13}$ Moreover, the spinal column was segmented into cervical, thoracic and lumbar spines with the same spring constant and damping coefficient. The basis for selecting the masses of these spinal segments was not reported in the study. Another eleven-DOF linear model for pregnant woman was proposed by Qassem and Othman. ${ }^{14}$ The responses of models ${ }^{13,14}$ did not match the experimentally identified ranges for the biodynamic responses. ${ }^{7}$

A four-DOF model was reported for essential dynamics of seated human body under the exposure of vibration. ${ }^{15}$ Another four-DOF linear model for a seated human body was proposed based upon STHT and DPMI data collected by experimentation with human subjects. ${ }^{5}$ All factors such as damping and elastic coefficients were obtained through an optimization procedure with human body anthropometric and biodynamic data 
as constraints. A thorough survey of the literature was performed on existing lumped parameter models for seated human body exposed to vertical vibration. ${ }^{7}$ It was found that the model developed by Wan and Schimmels matched with experimental data most closely. ${ }^{15}$

The lumped parameter model was a popular approach in comparison to the complex finite element model and multibody dynamic model approach, for the study of biodynamic responses of a seated human body. ${ }^{7}$ The simple human body model, which represents the essential operations, was beneficial compared to complex human body model not representing the required functioning. ${ }^{16}$ The transmission of vibration through the seated human body occurred via the spinal column of the human body, which affects spinal column adversely. ${ }^{2}$ In the present study, a six-DOF linear mathematical model, which captured the essential dynamics of spinal column for the seated human body exposed to vertical vibration, was proposed. The proposed model was based upon the frequency response functions: STHT and APMS which were selected based upon the comparative study of biodynamic response functions. ${ }^{17}$ The experimental data for frequency response functions: STHT and APMS, has been obtained by laboratory experimentation with seated human subjects. Also, analysis to find out the natural frequencies of the developed biodynamic model which was not attempted in the past studies has been performed in the present work.

\section{EXPERIMENTAL METHODOLOGY}

\subsection{Experimental Set-Up}

To identify the ranges for frequency response functions: STHT and APMS, the experiments were conducted on the vibration simulator available in the Vehicle Dynamics laboratory, Indian Institute of Technology Roorkee, India. The vibration simulator was developed as a mock-up of a railway vehicle compartment and used in many previous studies. ${ }^{18-21}$ The schematic diagram of vibration simulator is illustrated in Fig. 1(a). A table and two chairs were rigidly fixed on the platform of the vibration simulator. The chairs seats and backrests were both made of wood without cushions. None of the parts and accessories attached to the platform had shown any resonance in the considered frequency range. The airconditioned environment, which was set at a $26^{\circ} \mathrm{C}$ temperature with $57 \%$ RH humidity, was maintained inside the chamber. The test subjects were seated on the chairs that were rigidly mounted on the platform of the vibration simulator such that these were excited with the same frequency as the platform, up to $20 \mathrm{~Hz}$. The frequency of vibrations produced on board the railway vehicle ranges from 0.5 to $20 \mathrm{~Hz}$, which is also a critical range for the human beings. 2,3

\subsection{Subjects}

A total of eight healthy male subjects, aged 21 to 30 years participated in the experiment. The anthropometric data of subjects are presented in Table 1. All the participants were students (either graduate/postgraduate or research scholar) of the Institute. All the participants were required to sign a written
Table 1. Anthropometric data of subjects who participated in the experiment.

\begin{tabular}{|c|c|c|c|c|}
\hline & $\begin{array}{c}\text { Age } \\
(\text { years })\end{array}$ & $\begin{array}{c}\text { Height } \\
(\mathrm{cm})\end{array}$ & $\begin{array}{c}\text { Weight } \\
(\mathrm{kg})\end{array}$ & $\begin{array}{c}\text { Seated weight } \\
(\mathrm{kg})\end{array}$ \\
\hline Mean & 27 & 175.25 & 79.25 & 58.25 \\
\hline Standard deviation & 2.07 & 4.43 & 5.75 & 4.13 \\
\hline
\end{tabular}

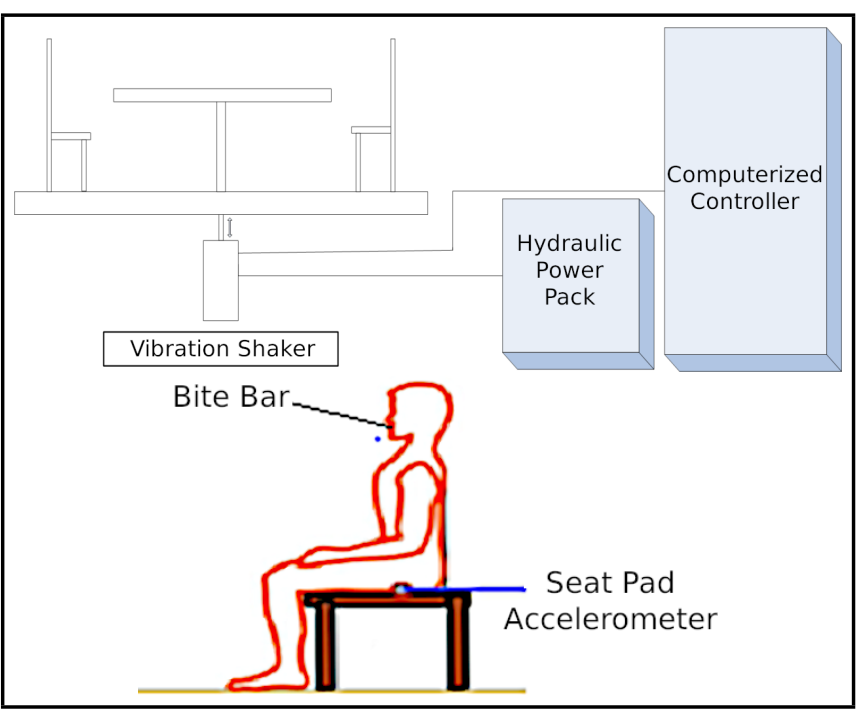

Figure 1. (a) Schematic diagram of computerized controlled vibration simulator and (b) posture adopted by the test subjects.

consent letter before participating in the experiment. A screening questionnaire was also filled by the participating subjects related to their personal background, fitness and musculoskeletal disorders. ${ }^{22}$ All the subjects were free from any musculoskeletal disorder and back pain. The subjects were informed about the experimental set-up and related emergency procedure. Approval for conducting the experiment had been obtained from the Institute Human Ethical Committee.

The experiment was performed on the seated test subjects in upright/erect posture without backrest (Fig. 1(b)). The hands were placed on the lap by the test subjects. Before conducting the experiment, all the subjects were instructed to maintain the desired posture and aim at the fixed and marked point in the line of sight, while performing the experiment.

\subsection{Instrumentation and Data Processing}

The random vibration (Gaussian random), nearly constant bandwidth acceleration power spectra in the considered frequency range $1-20 \mathrm{~Hz}$, were generated at $1.0 \mathrm{~m} / \mathrm{s}^{2} \mathrm{RMS}$ unweighted vibration magnitude.

Each experiment was repeated three times and mean of repeated two values had been considered. The measurement for each experiment lasted for $60 \mathrm{~s}$, with $2 \mathrm{~min}$ rest between the consecutive experiments. The platform vibrations were measured by mounting a tri-axial accelerometer (PCB PEZIOTRONICS-356A32). The seat vibration was measured with the help of a three-axis seat pad accelerometer (PCB PEZIOTRONICS 356B41). The head vibration was measured with the help of a sterilized bite-bar. ${ }^{23}$ An accelerometer (PCB PEZIOTRONICS 356A32) was mounted on the bite-bar gripped by the subjects in their teeth jaw during the experiment. A force platform consisting of four force transducer 
(Kistler 9066A4) was fixed with the chair seat for acquiring the driving force. Mass cancelation accounting for the upper plate and accessories of force platform was performed. The acceleration and force signals were acquired at a sampling rate of $128 \mathrm{~Hz}$ for 60 second time duration via a data acquisition device (NI cDAQ-9174). These signals were subsequently processed in Labveiw software to compute the APMS and STHT response function. The APMS and STHT responses were computed in following manner: ${ }^{24}$

$$
\begin{aligned}
& \operatorname{APMS}(\mathrm{j} \omega)=\frac{S_{i f}(f)}{S_{i i}(f)} ; \\
& \operatorname{STHT}(\mathrm{j} \omega)=\frac{S_{a i}(f)}{S_{i i}(f)} ;
\end{aligned}
$$

where $S_{i f}(f)$ : cross-spectral density of acceleration and force measured at driving point. $S_{o i}(f)$ : cross-spectral density of accelerations at driving point and head. $S_{i i}(f)$ : auto-spectral density of the driving point acceleration.

\section{MODEL DEVELOPMENT}

A biodynamic model on the basis of identified values of biodynamic responses was developed. The model parameters were calculated such that the APMS and STHT responses of models correlate reasonably with the identified ranges of APMS and STHT responses for seated subjects, in upright without backrest posture, under the exposure of vertical vibration at $1 \mathrm{~m} / \mathrm{s}^{2}$ magnitude. The proposed human seated model is illustrated in the Fig. 2. This model was proposed with the assumption of linearity in view of the biodynamic responses. ${ }^{25}$ The six masses represented the six human body segments: Head and neck $\left(M_{1}\right)$; thoracic spine $\left(M_{2}\right)$; upper torso and chest $\left(M_{3}\right)$; lower torso $\left(M_{4}\right)$; lumbar and sacrum spine $\left(M_{5}\right)$ and pelvis including mass of thighs $\left(M_{6}\right)$. The masses of lower legs and feet were not included due to their negligible contribution to the biodynamic responses. ${ }^{2}$

The summation of all the considered masses was equal to the seated weight of the test subjects. The stiffness and damping properties of between the different masses are represented by the $K_{i}$ and $C_{i}$; where, $1 \leq i \leq 8$.

The dynamics of the proposed model were expressed with the coupled differential equations as expressed below in the matrix form:

$$
[M]\{\ddot{X}\}+[C]\{\dot{X}\}+[K]\{X\}=[f]
$$

where mass matrix:

$$
[M]=\left[\begin{array}{cccccc}
M_{1} & 0 & 0 & 0 & 0 & 0 \\
0 & M_{2} & 0 & 0 & 0 & 0 \\
0 & 0 & M_{3} & 0 & 0 & 0 \\
0 & 0 & 0 & M_{4} & 0 & 0 \\
0 & 0 & 0 & 0 & M_{5} & 0 \\
0 & 0 & 0 & 0 & 0 & M_{6}
\end{array}\right]
$$

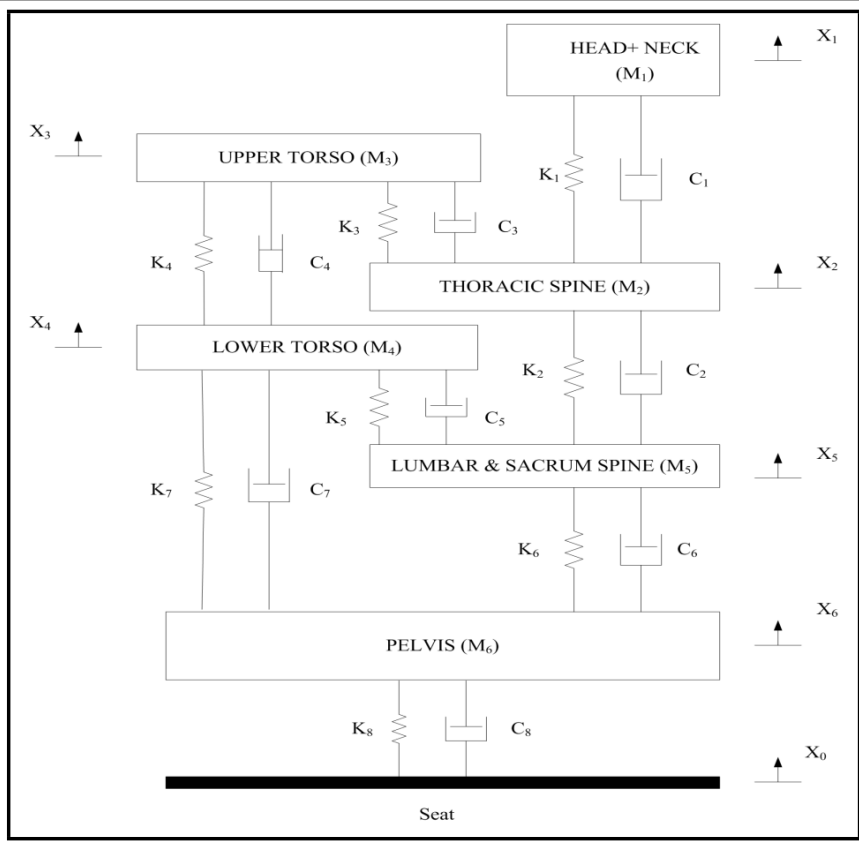

Figure 2. Six-DOF linear lumped parameter model for the seated human body under the exposure of vertical WBV.

damping matrix

$$
\begin{aligned}
& {[C]=\left[\begin{array}{cccc}
C_{1} & -C_{1} & 0 & \ldots \\
-C_{1} & C_{1}+C_{2}+C_{3} & -C_{3} & \ldots \\
0 & -C_{3} & C_{3}+C_{4} & \ldots \\
0 & 0 & -C_{4} & \ldots \\
0 & -C_{2} & 0 & \ldots \\
0 & 0 & 0 & \ldots
\end{array}\right.} \\
& \begin{array}{llll}
\ldots & 0 & 0 & 0
\end{array} \\
& \begin{array}{llll}
\ldots & 0 & -C_{2} & 0
\end{array} \\
& \begin{array}{llcl}
\ldots & -C_{4} & 0 & 0
\end{array} \\
& \ldots C_{4}+C_{5}+C_{7} \quad-C_{5} \quad-C_{7} \\
& \begin{array}{llll}
\ldots & -C_{5} & C_{2}+C_{5}+C_{6} & -C_{6}
\end{array} \\
& \begin{array}{llll}
\ldots & -C_{7} & -C_{6} & C_{6}+C_{7}+C_{8}
\end{array}
\end{aligned}
$$

stiffness matrix:

$$
\begin{aligned}
& {[K]=\left[\begin{array}{cccc}
K_{1} & -K_{1} & 0 & \cdots \\
-K_{1} & K_{1}+K_{2}+K_{3} & -K_{3} & \cdots \\
0 & -K_{3} & K_{3}+K_{4} & \cdots \\
0 & 0 & -K_{4} & \cdots \\
0 & -C_{2} & 0 & \cdots \\
0 & 0 & 0 & \cdots
\end{array}\right.} \\
& \left.\begin{array}{lccc}
\ldots & 0 & 0 & 0 \\
\ldots & 0 & -K_{2} & 0 \\
\ldots & -K_{4} & 0 & 0 \\
\ldots & K_{4}+K_{5}+K_{7} & -K_{5} & -K_{7} \\
\ldots & -K_{5} & K_{2}+K_{5}+K_{6} & -K_{6} \\
\ldots & -K_{7} & -K_{6} & K_{6}+K_{7}+K_{8}
\end{array}\right] \text {, }
\end{aligned}
$$

acceleration vector:

$$
\{\ddot{X}\}=\left[\begin{array}{c}
\ddot{X}_{1} \\
\ddot{X}_{2} \\
\ddot{X}_{3} \\
\ddot{X}_{4} \\
\ddot{X}_{5} \\
\ddot{X}_{6}
\end{array}\right]
$$


velocity vector:

$$
\{\dot{X}\}=\left[\begin{array}{c}
\dot{X}_{1} \\
\dot{X}_{2} \\
\dot{X}_{3} \\
\dot{X}_{4} \\
\dot{X}_{5} \\
\dot{X}_{6}
\end{array}\right]
$$

displacement vector:

$$
\{X\}=\left[\begin{array}{c}
X_{1} \\
X_{2} \\
X_{3} \\
X_{4} \\
X_{5} \\
X_{6}
\end{array}\right]
$$

and force vector:

$$
[f]=\left[\begin{array}{c}
0 \\
0 \\
0 \\
0 \\
0 \\
C_{8} \dot{X}_{0}+K_{8} X_{0}
\end{array}\right]
$$

The Apparent mass (APMS) of the seated human body was defined as the driving-point force to driving-point acceleration, and was derived in the frequency domain as follows:

$$
\operatorname{APMS}, Z(\mathrm{j} \omega)=\frac{\left(K_{8}+\mathrm{j} \omega C_{8}\right)\left[X_{0}(\omega)-X_{6}(\mathrm{j} \omega)\right]}{-\omega^{2} X_{0}(\omega)} \text {. }
$$

The seat-to-head transmissibility function is derived from:

$$
\operatorname{STHT}, T(\mathrm{j} \omega)=\frac{X_{1}(\mathrm{j} \omega)}{X_{0}(\omega)}
$$

Both, $Z(\mathrm{j} \omega)$ and $T(\mathrm{j} \omega)$, were complex functions, having magnitude as well as phase information.

\subsection{Goodness-of-fit $(\varepsilon)$}

To calculate the prediction accuracy of proposed model in contrast to frequency response functions computed experimentally, the ratio of the root-mean-square error to the mean value was evaluated as follows: ${ }^{26}$

$$
\varepsilon=100\left\{1-\frac{\sqrt{\sum\left(T_{e}-T_{m}\right)^{2} /(k-1)}}{\sum T_{e} / k}\right\}
$$

where $T_{e}$ was the experimental value at different frequencies. $T_{m}$ was the computed result from the model and $k$ was the number of frequencies, which was equal to 40 .

When $\varepsilon$ was equal to 100 , the fit of predicted results to experimental data was perfect. In the present study, the values for $\varepsilon$ were predicted for STHT, STHT phase, APMS magnitude and APMS phase for the proposed model.

\subsection{Model Parameter Identification}

The optimization procedure, with the help Genetic Algorithm tool available in MATLAB (R2010b), was performed. The objective function based upon the sum of squared error between the computed and the targeted experimental values for STHT and APMS responses (magnitude and phase) is formulated.

$$
Y(v)=\operatorname{Minimize}\left[y_{1}(v)+y_{2}(v)\right]
$$

$$
\begin{aligned}
y_{1}(v)=A \sum_{n=1}^{k}\left\{\left|Z\left(j \omega_{n}\right)\right|-\left|Z_{\mathrm{ex}}\left(j \omega_{n}\right)\right|\right\}^{2} \\
+B \sum_{n=1}^{K}\left\{\left|\phi\left(j \omega_{n}\right)\right|-\left|\phi_{\mathrm{ex}}\left(j \omega_{n}\right)\right|\right\}^{2} ;
\end{aligned}
$$

$$
\begin{aligned}
y_{2}(v)=C \sum_{n=1}^{k}\left\{\left|T\left(j \omega_{n}\right)\right|-\left|T_{\mathrm{ex}}\left(j \omega_{n}\right)\right|\right\}^{2} \\
+D \sum_{n=1}^{K}\left\{\left|\beta\left(j \omega_{n}\right)\right|-\left|\beta_{\mathrm{ex}}\left(j \omega_{n}\right)\right|\right\}^{2} ;
\end{aligned}
$$

where $\left|Z\left(j \omega_{n}\right)\right|,\left|\phi\left(j \omega_{n}\right)\right|$ and $\left|Z_{\mathrm{ex}}\left(j \omega_{n}\right)\right|,\left|\phi_{\mathrm{ex}}\left(j \omega_{n}\right)\right|$ were the magnitudes and phases for the computed and experimental values of APMS response respectivily. $\left|T\left(j \omega_{n}\right)\right|,\left|\beta\left(j \omega_{n}\right)\right|$ and $\left|T_{\mathrm{ex}}\left(j \omega_{n}\right)\right|,\left|\beta_{\mathrm{ex}}\left(j \omega_{n}\right)\right|$ were the magnitudes and phases for the computed and experimental values of the STHT responses respectively. $A, B, C$ and $D$ were weighting factors that were used for the contribution of STHT and APMS responses. $k$ was the total number of frequencies considered within the $0.5-20 \mathrm{~Hz} . v$ was a vector for computed parameter i.e. $v=\left\{C_{i}+K_{i}\right\}^{\prime} i=1,2, \ldots 8$.

\section{MODEL CONSTRAINTS}

The inertial properties of the model was identified on the basis of the height and weight of the participated subjects. The masses of head \& neck $\left(m_{1}\right)$, upper torso $\left(m_{3}\right)$, lower torso $\left(m_{4}\right)$, pelvis, and thighs $\left(m_{6}\right)$ of the model were computed by the procedure given by Zatsiorsky and Seluyanov. ${ }^{27}$ The masses of thoracic spine $\left(m_{2}\right)$ and lumber and sacrum spine $\left(m_{5}\right)$ were calculated on the basis of study done by Lowrance and Latimer. ${ }^{28}$

- Head and neck $\left(m_{1}\right)=5.15 \mathrm{~kg}$

- Thoracic spine $\left(m_{2}\right)=1.04 \mathrm{~kg}$

- Upper torso $\left(m_{3}\right)=28.18 \mathrm{~kg}$

- Lower torso $\left(m_{4}\right)=8.80 \mathrm{~kg}$

- Lumber and sacrum spine $\left(m_{5}\right)=1.74 \mathrm{~kg}$

- Pelvis and thighs $\left(m_{6}\right)=13.34 \mathrm{~kg}$

The identification of restoring and dissipative parameters entailed complexities during the development of the biodynamic model of human body. These parameters for the human body segments were comparatively unknown. The damping coefficients for the proposed human body model were kept 
Table 2. Identified model parameters.

\begin{tabular}{||l|l|}
\hline Damping Coefficients (Ns/m) & Stiffness Values (kN/m) \\
\hline$C_{1}=1582$ & $K_{1}=51$ \\
\hline$C_{2}=1736$ & $K_{2}=151$ \\
\hline$C_{3}=1653$ & $K_{3}=101$ \\
\hline$C_{4}=2114$ & $K_{4}=102$ \\
\hline$C_{5}=1488$ & $K_{5}=101$ \\
\hline$C_{6}=2059$ & $K_{6}=101$ \\
\hline$C_{7}=2952$ & $K_{7}=102$ \\
\hline$C_{8}=2762$ & $K_{8}=101$ \\
\hline
\end{tabular}

within $500-4000 \mathrm{Ns} / \mathrm{m}$ range. ${ }^{29}$ In a study on the human vertebral column, ${ }^{30}$ the stiffness values for the thoracic and lumbar spine was identified to be $150-200 \mathrm{kN} / \mathrm{m}$ and $100-300 \mathrm{kN} / \mathrm{m}$ respectively. The stiffness values for the thoracic and lumbar spine were constrained within the identified range. ${ }^{30}$ For rest of the segments, the stiffness values were constrained for greater than zero.

\section{RESULTS AND DISCUSSIONS}

The experiments were performed with test subjects seated in upright posture under the exposure of vertical WBV. The ranges for frequency response functions were identified as an outcome of the experiments. The mean values for STHT and STHT phase with an envelope of maximum and minimum values have been identified, Fig. 3. The peak value of STHT, for all the participated subjects, occurs in the $4-5.5 \mathrm{~Hz}$ range of frequency. The primary peak in mean STHT occurs at $5 \mathrm{~Hz}$ of frequency with a secondary peak at $11 \mathrm{~Hz}$ of frequency. The mean values for APMS magnitudes and APMS phase with an envelope of maximum \& minimum values have been identified, Fig. 4. The peak value of APMS magnitude, for all the participated subjects, occurs in the $3-6 \mathrm{~Hz}$ range of frequency. The primary peak in mean APMS magnitude occurs at $5 \mathrm{~Hz}$ of frequency. The secondary peak in the mean APMS magnitude has not been observed. The primary peak within the 4-6 Hz frequency range and secondary peak within $8-12 \mathrm{~Hz}$ frequency range, for the biodynamic responses, have been observed in the past studies. ${ }^{31,32}$ The mean values illustrated in Fig. 3 and 4, are considered as a target values to search the restoring and dissipative properties of the model through optimization process.

Using the values of upper bound and lower bound values of model parameters, i.e. $C_{i} s$ and $K_{i} s$, sequential search for the model parameters was performed to optimize the objective function defined in Eq. (6). When the objective function reaches the minimum value, the search was terminated. The solution for the optimization of objective function resulted in the identification of the model parameters for the seated human body in upright posture (Table 2).

The comparisons of the calculated characteristics (STHT, STHT phase, APMS magnitude and APMS phase) from the model, with mean the values of targeted characteristics are illustrated in Fig. 5 and 6. Also, the value for goodness of fit $(\varepsilon)$, for the respective figure, has been shown. The resonant frequency of the model is found to be $4.5 \mathrm{~Hz}$, compared to $5 \mathrm{~Hz}$ estimated experimentally. The goodness of fit $(\varepsilon)$, which is calculated from the model and target values, is $85.9 \%$ for the

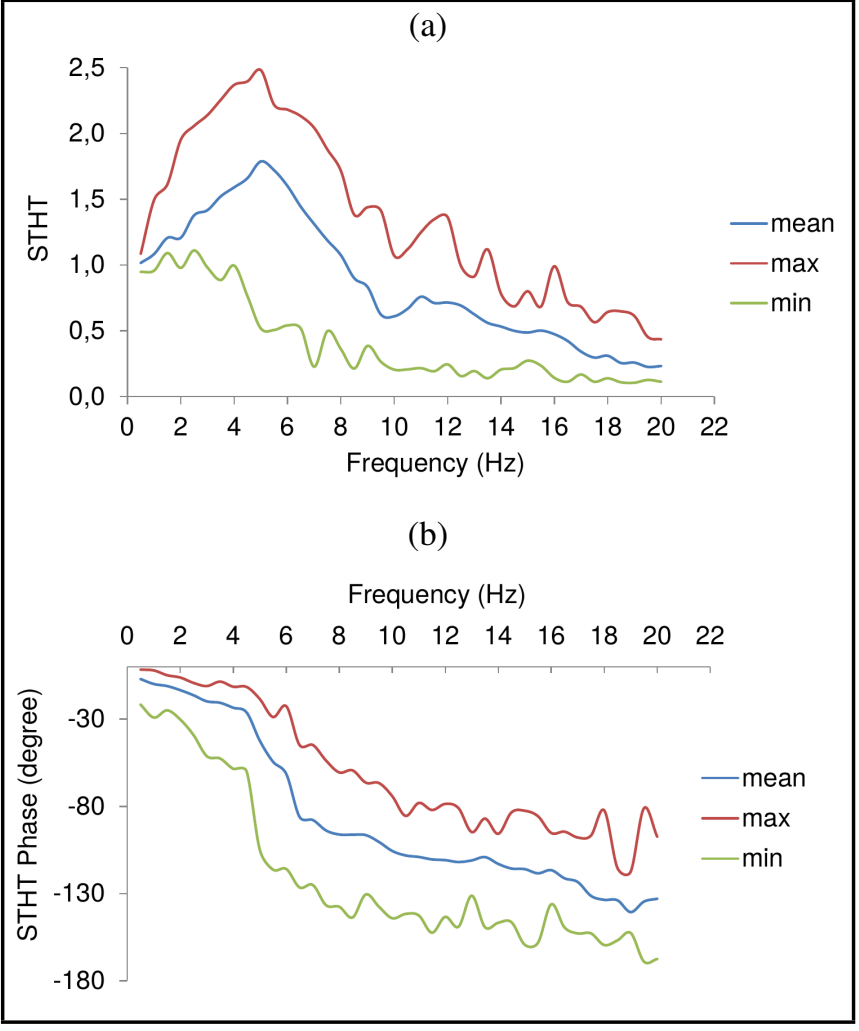

Figure 3. Mean and envelope of maximum and minimum values of (a) STHT magnitude and (b) phase.

(a)

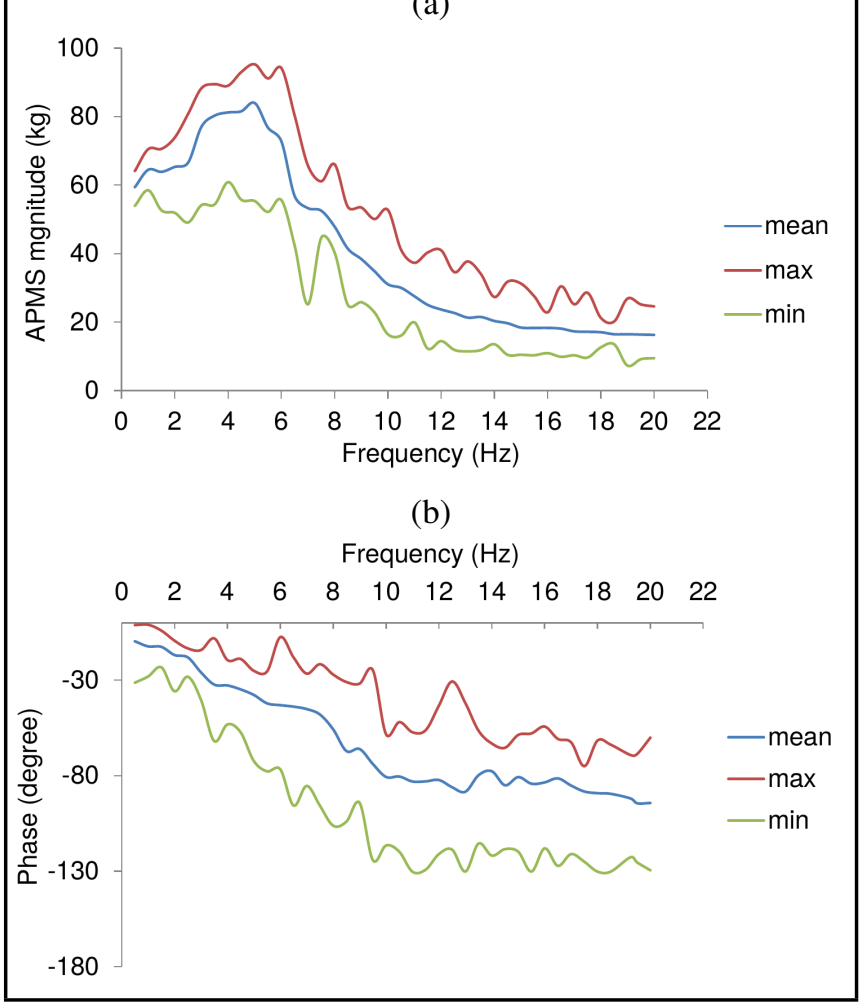

Figure 4. Mean and envelope of maximum and minimum values of (a) APMS magnitude and (b) phase. 


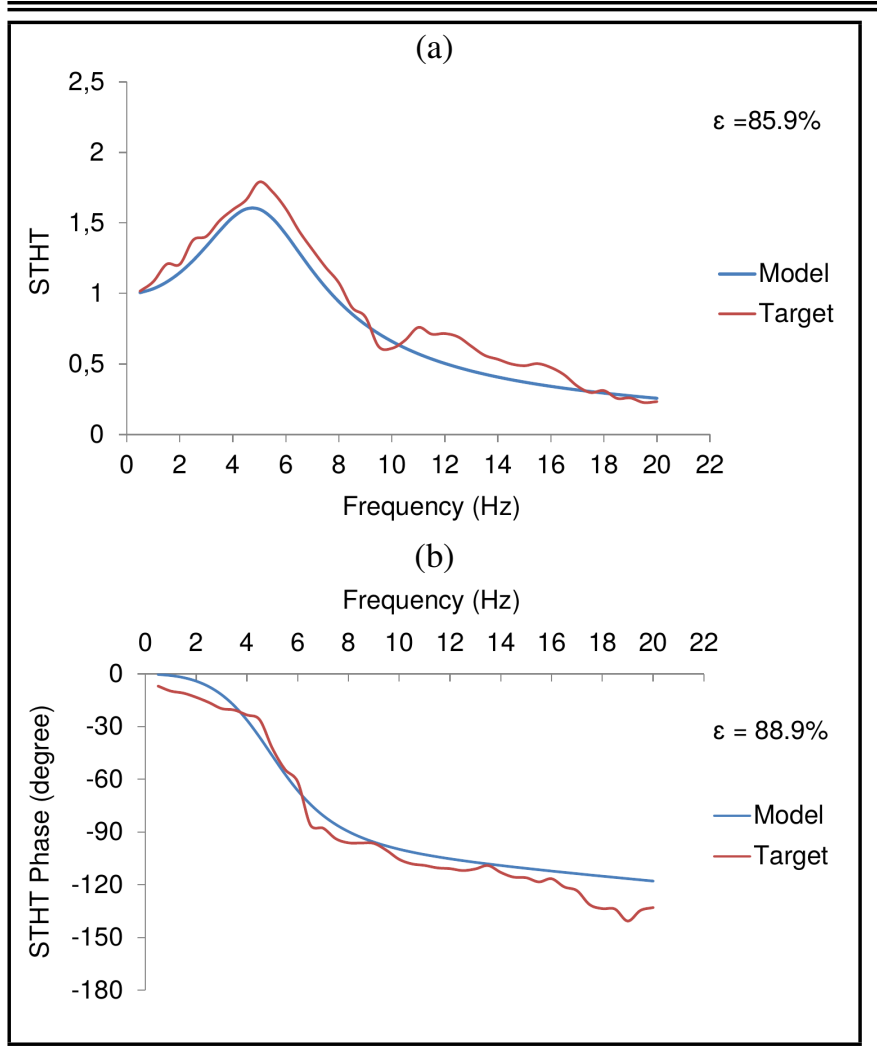

Figure 5. Comparison of (a) STHT magnitude and (b) STHT phase calculated from the proposed model with the respective target values computed experimentally.

STHT. For the STHT phase responses, the goodness of fit $(\varepsilon)$ is $88.9 \%$. The resonant peak for APMS magnitude calculated from the model occurs at $4.5 \mathrm{~Hz}$ of frequency whereas that for targeted values occurs at $5 \mathrm{~Hz}$ of frequency. There is less than $5 \%$ of error in peak APMS magnitude calculated from the model and targeted value. The goodness of fit $(\varepsilon)$ calculated for APMS magnitude and APMS phase are $91.2 \%$ and $79.1 \%$ respectively, also shown in Fig. 6.

\subsection{Parameter Sensitivity Test}

The effects of changes in the model parameters (masses, stiffness, and damping coefficients) on the resonance frequencies and the magnitudes at resonance in STHT and APMS for vertical vibration are studied. For the predicted mean response, each model parameter is allowed to change by $\pm 30 \%$ from the optimized value while the other parameters are fixed at the optimized values and tabulated in Table 3 . This helps to identify the segments of the model producing the resonance behavior.

Table 3 shows the influence of model parameters on the resonance frequencies, STHT and APMS responses. The greatest changes in the resonance frequencies of STHT and magnitude of STHT occurred with changes in $M_{3}, K_{8}$ and $C_{8}$. The largest changes in the resonance frequencies of APMS and magnitude of APMS result from variations in $M_{3}, K_{7}, C_{7}$ and $M_{3}, K_{8}$, $C_{8}$ respectively. However, some other parameters $\left(M_{1}, M_{4}\right.$, $M_{6}, K_{1}, K_{6}, K_{7} C_{4}, C_{6}$ and $C_{7}$ ) show lower influence on resonance frequencies, STHT and APMS. Therefore, it can be concluded that the responses are mainly produced by the system represented by the parameters $M_{3}, K_{7}, K_{8}, C_{7}$ and $C_{8}$ (mass of upper torso, stiffness and damping parameters be- (a)

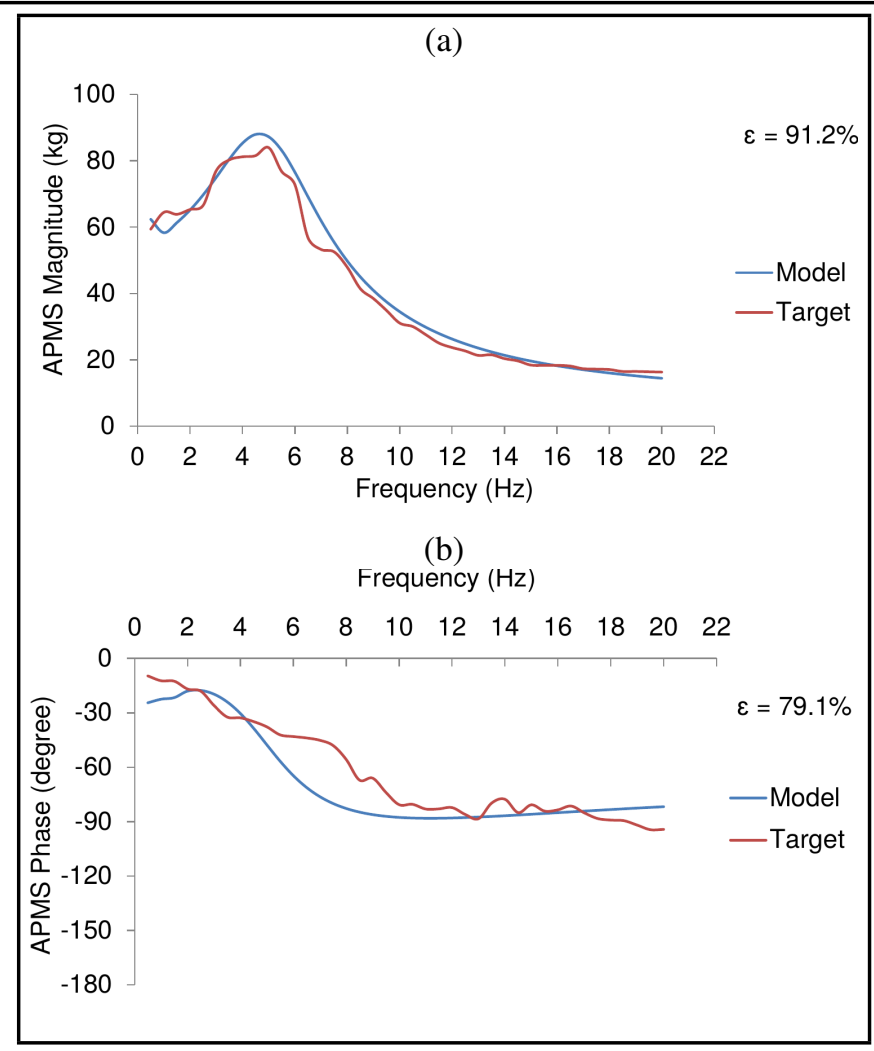

Figure 6. Comparison of (a) APMS magnitude and (b) APMS phase calculated from the proposed model with the respective target values computed experimentally.

tween the lower torso and pelvis and beneath the pelvis).

The restoring and dissipative parameters identified represent a compromise to accomplish acceptable values of APMS and STHT responses. Larger variability can be observed for damping coefficients as compared to the stiffness values for the proposed model. These identified parameters have been evaluated on the basis of targeted frequency response characteristics, whilst the actual damping coefficients and stiffness values of the human body segments may be different. The goodness of fit is essential because it describes the degree to which a model satisfies the physical characteristics. In most of the studies the peak in the biodynamic responses has been observed around $5 \mathrm{~Hz}$ frequencies which are also considered as a resonance frequency for the human body. For the proposed model in the present study, the peak occurs at near $5 \mathrm{~Hz}$ for both the responses i.e. STHT magnitude and APMS magnitude. The proposed model may be considered appropriate to provide satisfactory results of biodynamic responses of seated human body under the exposure of WBV.

\subsection{Natural Frequency Analysis}

Natural frequencies of the developed model have been found, results tabulated in Table 4.

The developed biodynamic model will be in a resonating state at the presented natural frequencies. The natural frequencies of the biodynamic model provide insight into the behavior of the human body under the exposure of vibration having the frequencies which matches with the natural frequencies of the model. These natural frequencies can be further used to identify the various effects of the vibration exposure. 
Table 3. Resonance frequencies, STHT and APMS at resonance calculated after $\pm 30 \%$ change in each model parameter.

\begin{tabular}{||l|l|l|l|l|l|l|l|l||}
\hline \multirow{2}{*}{} & \multicolumn{2}{|c|}{ Frequency } & \multicolumn{2}{c|}{ STHT } & \multicolumn{2}{c|}{ Frequency } & \multicolumn{2}{c|}{ AMPS } \\
\cline { 2 - 10 } & $-30 \%$ & $+30 \%$ & $-30 \%$ & $+30 \%$ & $-30 \%$ & $+30 \%$ & $-30 \%$ & $+30 \%$ \\
\hline$M_{1}$ & 4.84 & 4.74 & 1.63 & 1.71 & 4.84 & 4.70 & 80.93 & 93.57 \\
\hline$M_{2}$ & 4.80 & 4.79 & 1.66 & 1.67 & 4.78 & 4.76 & 86.44 & 87.87 \\
\hline$M_{3}$ & 5.26 & 4.43 & 1.60 & 1.73 & 5.20 & 4.43 & 70.32 & 105.17 \\
\hline$M_{4}$ & 4.87 & 4.72 & 1.65 & 1.69 & 4.85 & 4.69 & 83.23 & 91.14 \\
\hline$M_{5}$ & 4.81 & 4.78 & 1.66 & 1.67 & 4.79 & 4.76 & 86.31 & 87.99 \\
\hline$M_{6}$ & 4.84 & 4.75 & 1.65 & 1.69 & 4.83 & 4.71 & 83.26 & 91.11 \\
\hline$K_{1}$ & 4.75 & 4.81 & 1.69 & 1.67 & 4.71 & 4.79 & 91.11 & 86.05 \\
\hline$K_{2}$ & 4.75 & 4.82 & 1.68 & 1.66 & 4.72 & 4.80 & 89.81 & 85.19 \\
\hline$K_{3}$ & 4.77 & 4.82 & 1.66 & 1.68 & 4.75 & 4.79 & 85.92 & 88.02 \\
\hline$K_{4}$ & 4.70 & 4.86 & 1.66 & 1.67 & 4.67 & 4.83 & 88.31 & 85.92 \\
\hline$K_{5}$ & 4.79 & 4.80 & 1.67 & 1.67 & 4.77 & 4.77 & 87.04 & 87.24 \\
\hline$K_{6}$ & 4.69 & 4.87 & 1.65 & 1.68 & 4.65 & 4.86 & 88.45 & 85.73 \\
\hline$K_{7}$ & 4.68 & 4.89 & 1.64 & 1.69 & 4.63 & 4.88 & 87.65 & 86.28 \\
\hline$K_{8}$ & 4.78 & 5.03 & 1.70 & 1.82 & 4.83 & 4.97 & 84.93 & 97.08 \\
\hline$C_{1}$ & 4.84 & 4.77 & 1.70 & 1.65 & 4.80 & 4.76 & 88.88 & 85.63 \\
\hline$C_{2}$ & 4.82 & 4.77 & 1.68 & 1.66 & 4.79 & 4.75 & 87.66 & 86.57 \\
\hline$C_{3}$ & 4.78 & 4.81 & 1.67 & 1.67 & 4.77 & 4.77 & 87.27 & 87.12 \\
\hline$C_{4}$ & 4.84 & 4.77 & 1.69 & 1.65 & 4.83 & 4.73 & 88.76 & 85.67 \\
\hline$C_{5}$ & 4.79 & 4.80 & 1.67 & 1.67 & 4.77 & 4.77 & 87.15 & 87.16 \\
\hline$C_{6}$ & 4.83 & 4.77 & 1.70 & 1.64 & 4.81 & 4.74 & 89.38 & 85.10 \\
\hline$C_{7}$ & 4.84 & 4.78 & 1.72 & 1.64 & 4.84 & 4.73 & 90.77 & 84.16 \\
\hline$C_{8}$ & 4.93 & 4.75 & 1.92 & 1.53 & 4.87 & 4.83 & 95.05 & 84.33 \\
\hline
\end{tabular}

Table 4. Natural frequencies of the biodynamic model

\begin{tabular}{|l|}
\hline$f_{1}=0.16586 \mathrm{~Hz}$ \\
\hline$f_{2}=0.46627 \mathrm{~Hz}$ \\
\hline$f_{3}=0.59044 \mathrm{~Hz}$ \\
\hline$f_{4}=1.0037 \mathrm{~Hz}$ \\
\hline$f_{5}=3.0629 \mathrm{~Hz}$ \\
\hline$f_{6}=5.0896 \mathrm{~Hz}$ \\
\hline
\end{tabular}

The restoring and dissipative parameters identified (Table 2) represents a compromise to accomplish acceptable values of APMS and STHT responses. Significant variability has been observed in the identified damping coefficients compared to the identified stiffness values for the proposed values. These identified parameters assume the values on the basis of targeted frequency response characteristics. However the actual damping coefficients and stiffness values of the human body parts may vary compared to the identified parameters for the model. Various models have been proposed in the literature, which satisfying only one of the biodynamic responses. The goodness of fit for the model characteristics and the targeted characteristics is reported in very few studies. The goodness of fit is essential to represents because it describe the degree to which model satisfy the physical characteristics. A thorough study has been performed for all reported biodynamic models of seated human body under the vertical WBV exposure, in literature, ${ }^{7}$ and goodness of fit was calculated and compared for all the reported models for the biodynamic characteristics. For the proposed model in the present study, the peak occurs at near $5 \mathrm{~Hz}$ for both the responses i.e. STHT and APMS magnitude. The goodness of fit for the APMS magnitude is comparatively higher than that for STHT magnitude. The developed model may be considered appropriate to provide satisfactory results of biodynamic responses of seated human body under the exposure of vertical WBV.

\section{CONCLUSIONS}

This work proposes a six-DOF linear lumped parameter model to represent the seat-to-head transmissibility and apparent mass responses of the human body seated in upright posture without backrest. The model provide reasonable estimate of the target values of apparent mass magnitude and seatto-head transmissibility under the considered conditions. The goodness of fit for the apparent mass magnitude and seat-tohead transmissibility is $91.2 \%$ and $85.9 \%$ respectively. The model represents the resonant frequency near $5 \mathrm{~Hz}$ in both the considered biodynamic responses. The methodology could be used for identifying the new sets of restoring and dissipative parameters to better satisfy the biodynamic characteristics applicable under different conditions.

\section{REFERENCES}

1 Bovenzi, M., and Hulshof, C. T. J. An updated review of epidemiologic studies on the relationships between exposure to whole body vibration and low back pain. J. Sound Vib. 215 595-611. 1998. https://dx.doi.org/10.1007/s004200050387

2 Griffin, M.J. Handbook of Human Vibration, second Ed. Academic Press Limited, London. 2003.

3 Mansfield, N.J. Human Response to Vibration. CRC Press, London. 2005. https://dx.doi.org/10.1201/b12481

${ }^{4}$ Fairley, T. E., and Griffin, M. J. The apparent mass of the seated human body: vertical vibration. Journal of Biomechanics 22, 81-94. 1989. https://dx.doi.org/10.1016/00219290(89)90031-6

5 Boileau, P.-E., and Rakheja, S. Whole-body vertical biodynamic response characteristics of the seated vehicle driver measurement and model development. International Journal of Industrial Ergonomics 22, 449-472. 1998. https://dx.doi.org/10.1016/S0169-8141(97)00030-9

6 Coermann, R.R. The mechanical impedance of the human body in sitting and standing positions at low frequencies. Human Factors 4, 227-253. 1962. https://dx.doi.org/10.1177/001872086200400502

7 Liang, C.C., and Chiang, C.F. A study on biodynamic models of seated human subjects exposed to vertical vibration. International Journal of Industrial Ergonomics 36, 869-90. 2006. https://dx.doi.org/10.1016/j.ergon.2006.06.008

8 Singh, I., Nigam, S. P., and Saran, V. H. Modal analysis of human body vibration model for Indian subjects under sitting posture. Ergonomics ahead-of-print 1-16. 2014. https://dx.doi.org/10.1080/00140139.2014.961567

9 Suggs, C. W., Abrams, C. F., and Stikeleather, I. F. Application of a damped spring-mass human vibration simulator in vibration testing of vehicle seats. Ergonomics 12, 79-90. 1969. https://dx.doi.org/10.1080/00140136908931030 
10 Muksian, R. and Nash, C.D. A model for the response of seated humans to sinusoidal displacements of the seat. Journal of Biomechanics 7, 209-215. 1974. https://dx.doi.org/10.1016/0021-9290(74)90011-6

11 Muksian, R., and Nash, C.D. On frequency-dependent damping coefficients in lumped-parameter models of human beings. Journal of Biomechanics 9, 339-342. 1976. https://dx.doi.org/10.1016/0021-9290(76)90055-5

12 Patil, M.K. and Palanichamy, M.S. A mathematical model of tractor-occupant system with a new seat suspension for minimization of vibration response. Applied Mathematical Modelling 12, 63-71. 1988. https://dx.doi.org/10.1016/0307-904X(88)90024-8

13 Qassem, W., Othman, M.O. and Abdul-Majeed, S. The effects of vertical and horizontal vibrations on the human body. Medical Engineering Physics 16, 151-161. 1994. https://dx.doi.org/10.1016/1350-4533(94)90028-0

14 Qassem, W. and Othman, M.O. Vibration effects on sitting pregnant women-subjects of various masses. Journal of Biomechanics 29 (4), 493-501. 1996. https://dx.doi.org/10.1016/0021-9290(95)00074-7

15 Wan, Y. and Schimmels, J.M. A simple model that captures the essential dynamics of a seated human exposed to whole body vibration. Advances in Bioengineering, ASME, BED 31, 333-334. 1995.

16 Griffin, M.J. The validation of biodynamic models. Clinical Biomechanics 16, S81-S92 2001. https://dx.doi.org/10.1016/S0268-0033(00)00101-7

$17 \mathrm{Wu}$, X., Rakheja, S. and Boileau, P.E. Analysis of relationships between biodynamic response functions, Journal of Sound and Vibration 226 (3) 595-606. 1999. https://dx.doi.org/10.1006/jsvi.1999.2267

18 Bhiwapurkar, M.K., Saran, V.H., Harsha, S.P., Goel, V.K., and Berg, M. Effect of magnitudes and directions (monoaxis and multi-axis) of whole body-vibration exposures and subjects postures on the sketching performance. Proceedings of the Institution of Mechanical Engineers, Part F: Journal of Rail and Rapid Transit 225, 71-83. 2010. https://dx.doi.org/10.1243/09544097JRRT336

19 Bhiwapurkar, M.K., Saran, V.H., Harsha, S.P., Goel V.K., and Berg M. Influence of Mono-axis Random Vibration on Reading Activity. Industrial Health, 48, 675-681. 2010. https://dx.doi.org/10.2486/indhealth.MSWBVI-09

20 Bhiwapurkar, M.K., Saran V.H., and Harsha, S.P. Objective and subjective responses of seated subjects while reading Hindi newspaper under multi axis whole-body vibration. Int.Jnl. of Industrial Ergonomics, 141, 625-633. 2011. https://dx.doi.org/10.1016/j.ergon.2011.06.004
21 Kumar, V., and Saran, V. H. Influence of reading format on reading activity under uniaxial whole body vibration. International Journal of Industrial Ergonomics 44, 520-527. 2014. https://dx.doi.org/10.1016/j.ergon.2014.05.004

22 Kuorinka, I., Jonsson, B., Kilbom, A., Vinterberg, H., Biering-Sørensen, F., Andersson, G., and Jørgensen, K. Standardised nordic questionnaires for the analysis of musculoskeletal symptoms. Applied Ergonomics 18, 233-237 1987. https://dx.doi.org/10.1016/0003-6870(87)90010-X

23 Bhiwapurkar, M.K. Effect of whole body vibration an activity comfort. Doctoral theses, IIT Roorkee 2011.

24 Bendat, J.S. and Piersol, A.G. Random Data-analysis and Measurement Procedures. Wiley, New York. 1992.

25 IS/ISO 5982 2001. Mechanical vibration and shock range of idealized values to characterize seated-body biodynamics response under vertical vibration.

26 Wong, J.Y. Terramechanics and Off-road Vehicles. Elsevier Science Publishing Company, New York. 1989.

27 Zatsiorsky, V.M., Seluyanov, V.N. The mass and inertia characteristics of the main segments of the human body. In: Matsui H, Kabayashi K, editors. Biomechanics VIII-B. Champaign (IL): Human Kinetics. 1983.

28 Lowrance, E.W., and Latimer, H.B. Weights and variability of components of the human vertebral column. Anatomical Record, 159, 83-88. 1967. https://dx.doi.org/10.1002/ar.1091590112

29 Mertens, H. Nonlinear behaviour of sitting humans under increasing gravity. Aviation Space and Environmental Medicine, 287-298. 1978.

30 Kazarian, L. Dynamic Response Characteristics of the Human Vertebral Column. Trycheri Balder, Stockholm. 1972. https://dx.doi.org/10.3109/ort.1972.43.suppl-146.01

31 Mansfield, N.J., and Griffin, M.J. Non-linearities in apparent mass and transmissibility during exposure to whole-body vertical vibration, Journal of Biomechanics 33 933-941. 2000. https://dx.doi.org/10.1016/S00219290(00)00052-X

32 Wang, W., Rakheja, S. and Boileau, P-É. Relationship between measured apparent mass and seat-to-head transmissibility responses of seated occupants exposed to vertical vibration. Journal of Sound and Vibration 314 (3-5), 907922. 2008. https://dx.doi.org/10.1016/j.jsv.2008.01.015 